\title{
Predicting adverse drug reactions in older adults; a systematic review of the risk prediction models
}

\author{
This article was published in the following Dove Press journal: \\ Clinical Interventions in Aging \\ 19 September 2014 \\ Number of times this article has been viewed
}

\section{Jennifer M Stevenson ${ }^{1,2}$ Josceline L Williams ${ }^{1,2}$ Thomas G Burnham² A Toby Prevost ${ }^{3}$ Rebekah Schiff ${ }^{4}$ \\ $S$ David Erskine ${ }^{2}$ J Graham Davies'}

'Institute of Pharmaceutical Sciences, King's College London, London, UK; 2Pharmacy Department, St Thomas' Hospital, Guy's and St Thomas' NHS Foundation Trust, London, UK; ${ }^{3}$ Department of Primary Care and Public Health Sciences, King's College London, London, UK; ; ${ }^{4}$ Department of Ageing and Health, Guy's and St Thomas' NHS Foundation Trust, London, UK
Correspondence: J Graham Davies Institute of Pharmaceutical Sciences, King's College London, I 50 Stamford Street, London, SEI 9NH, UK Tel +440207484 4049 Fax +44020 7484 478I Email graham.davies@kcl.ac.uk Jennifer M Stevenson Institute of Pharmaceutical Sciences, King's College London, I 50 Stamford Street, London, SEI 9NH, UK

$\mathrm{Tel}+4402074844834$

Fax +44 0207484 478I

Email jennifer.stevenson@kcl.ac.uk
Abstract: Adverse drug reaction (ADR) risk-prediction models for use in older adults have been developed, but it is not clear if they are suitable for use in clinical practice. This systematic review aimed to identify and investigate the quality of validated ADR risk-prediction models for use in older adults. Standard computerized databases, the gray literature, bibliographies, and citations were searched (2012) to identify relevant peer-reviewed studies. Studies that developed and validated an ADR prediction model for use in patients over 65 years old, using a multivariable approach in the design and analysis, were included. Data were extracted and their quality assessed by independent reviewers using a standard approach. Of the 13,423 titles identified, only 549 were associated with adverse outcomes of medicines use. Four met the inclusion criteria. All were conducted in inpatient cohorts in Western Europe. None of the models satisfied the four key stages in the creation of a quality risk prediction model; development and validation were completed, but impact and implementation were not assessed. Model performance was modest; area under the receiver operator curve ranged from 0.623 to 0.73 . Study quality was difficult to assess due to poor reporting, but inappropriate methods were apparent. Further work needs to be conducted concerning the existing models to enable the development of a robust ADR risk-prediction model that is externally validated, with practical design and good performance. Only then can implementation and impact be assessed with the aim of generating a model of high enough quality to be considered for use in clinical care to prioritize older people at high risk of suffering an ADR.

Keyword: aged, stratified care, prognosis, medication-related harm

\section{Introduction}

Adverse drug reactions (ADRs) have long been recognized as a potential outcome of taking medicines, and while the severity of such reactions may vary, a significant proportion of ADRs are responsible for hospital admissions. ${ }^{1}$ Investigators have strived to identify the key factors that increase a person's risk of suffering an ADR, especially in older adults, a group nearly seven-times more likely to be hospitalized due to an ADR when compared to younger people. ${ }^{2}$

We know that the changes in drug pharmacokinetic and pharmacodynamic properties that occur as a result of the aging process often lead to an increased susceptibility to ADRs. ${ }^{3}$ Polypharmacy, a frequently reported risk factor for ADRs, ${ }^{4}$ is on the increase as people live longer with multiple chronic conditions, so stratifying an older patient's risk of suffering an ADR might be attractive.

Risk prediction is a routine component of everyday medicine in both specific areas (for example, approaches used to determine stroke risk in patients with atrial fibrillation $)^{5}$ as well as more generally, to identify patients at risk of hospital admission. ${ }^{6}$ ADR risk stratification in older adults could assist in case prioritization, supporting 
clinicians and patients to make informed decisions about treatments and for the delivery of a more efficient health care service.

Accurate risk prediction models are the result of four key stages: development, validation, impact, and implementation. ${ }^{7}$ It is recognized that often only the first two stages (ie, development and validation) are completed, the methods and outcomes of which are often poorly reported. ${ }^{7}$ Furthermore, to be of practical use, these models should use clearly defined easily obtainable data, have good predictive power, be tested in a large sample representative of the target population, and have high reliability and face validity. ${ }^{7}$ A recent systematic review emphasized that failure to consider risk prediction in a clinical setting can result in poor care. ${ }^{8}$ With regard to the prediction of medication risk in older adults, as no systematic review of this area has been undertaken, we aim to identify and assess the quality of validated ADR risk-prediction models for use in adults over 65 years of age in order to determine their potential benefit to clinical practice.

\section{Method}

\section{Information sources and search}

A systematic search for published material was performed, up to November 30, 2012, using standard databases (Embase, Medline, Cochrane Library, BNI, CINAHL, NeLM, IPA) to identify relevant studies as well as those associated with policy documents and unpublished work (Department of Health, King's Fund, Worldcat, Open Grey, Google Scholar). For the key studies, the bibliographies and citations were reviewed, and an author search was performed, to identify any additional studies.

Our search strategies for each database included no restrictions and used standard terms based around three key concepts: older people; medication-related problems; and clinical prediction models. The full Embase search strategy is provided in Table $\mathrm{S} 1$.

\section{Inclusion criteria and selection}

Two researchers (JMS and SDE) independently screened titles, abstracts, and, where necessary, full texts in order to identify studies that potentially satisfied the following inclusion criteria:

- Majority of patients $\geq 65$ years old

- Included patients who experienced an adverse drug event (ADE) or ADR but excluded prescription errors

- A multivariable approach in design and analysis was followed

- The model had been validated.

\section{Data extraction}

Data were extracted (by JMS) to provide details of the population characteristics, study design, process of model development and validation, and performance of the model, as presented in Tables 1 and 2. This was confirmed by secondary reviewers (SDE and ATP) and, where disagreement occurred, this was resolved through discussion.

\section{Quality assessment}

All papers were initially reviewed (SDE and JMS) using a standard approach for developing and testing clinical prediction models to satisfy a range of criteria representing four stages: development (identification of candidate predictor variables and model design); validation (testing the performance of the model); impact (measurement of usefulness in the clinical setting); and implementation (widespread acceptance and adoption in clinical practice). ${ }^{7}$

As no standardized quality assessment for risk-prediction models is available, each study was analyzed using criteria derived from the published literature. ${ }^{8-11}$ Candidate predictor variables were grouped into three categories to allow for comparison between studies: demographic factors; medical factors (eg, comorbidities); and medication factors (eg, class of medicine). Event rate was calculated as percentage ADR/ADE rate where it was not reported by the authors in this form. Quality of design and reporting of the studies was compared based on ability to comply with the standard criteria (Table S2). The overall performance of the models was determined by review of their accuracy, discrimination, and calibration through internal or external validation, as described in detail in Table S2.

\section{Results}

A total of 13,423 potentially relevant titles were identified from the literature, of which only 549 were associated with adverse outcomes of medicines use. The majority of these (535) were excluded on review of their abstract as they were not associated with the design of a risk prediction model; many of these were observational (see Figure 1). Full papers were requested for the remaining 14 articles for further scrutiny, and four met the inclusion criteria and were subjected to a full evaluation. ${ }^{12-15}$

\section{Excluded papers}

The 535 articles excluded could be categorized into observational studies (325), those in which indicators to support quality prescribing were developed (63 studies; for example Beers' criteria ${ }^{16}$ ), and those applying the prescribing indicators (147 studies) to determine any association between inappropriate medicines and adverse outcomes. 


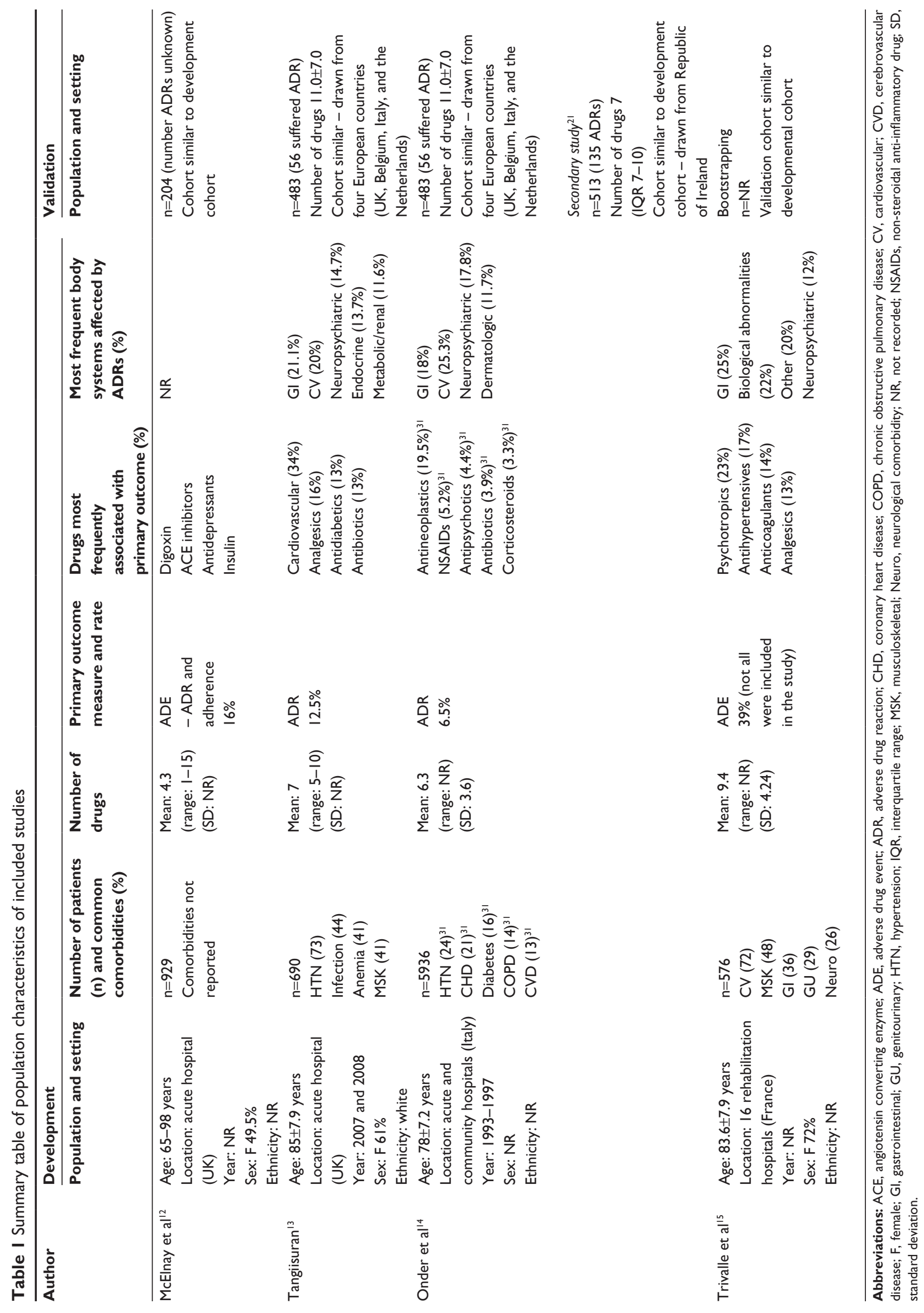



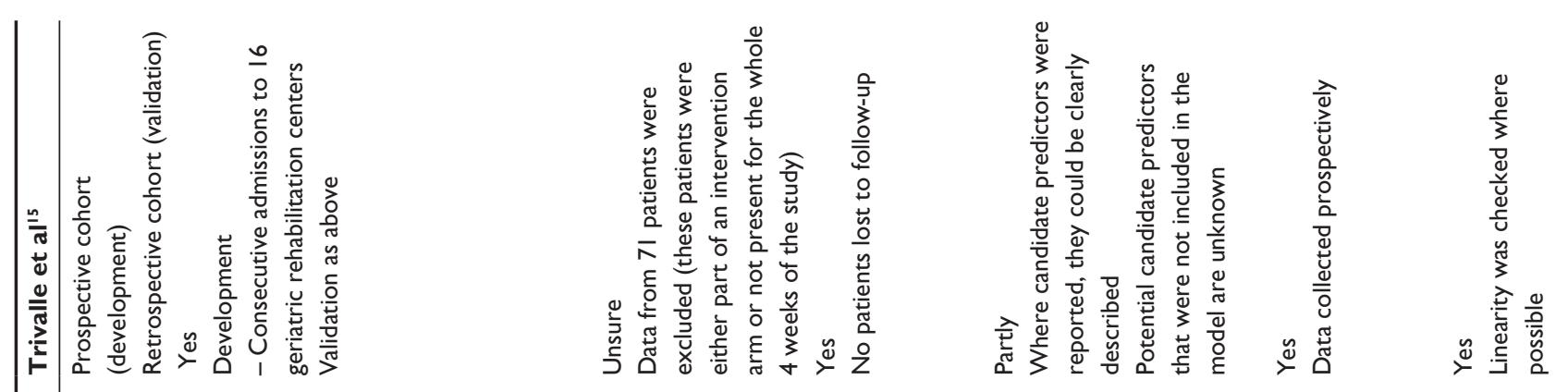

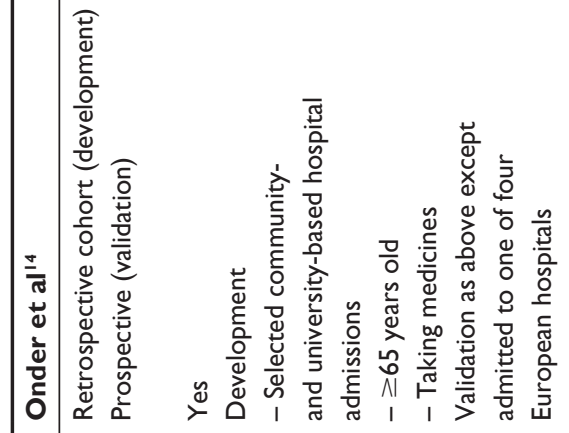
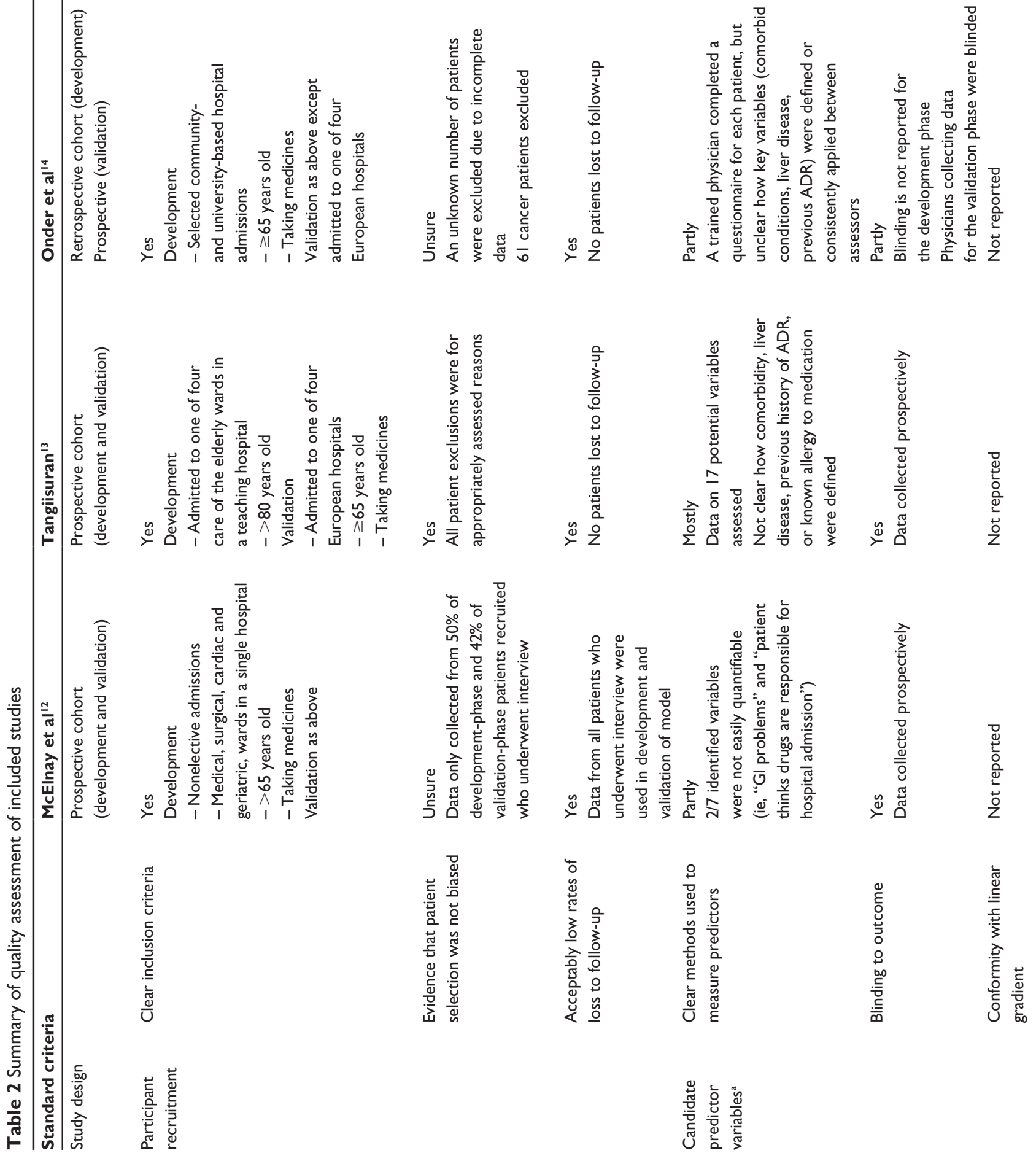

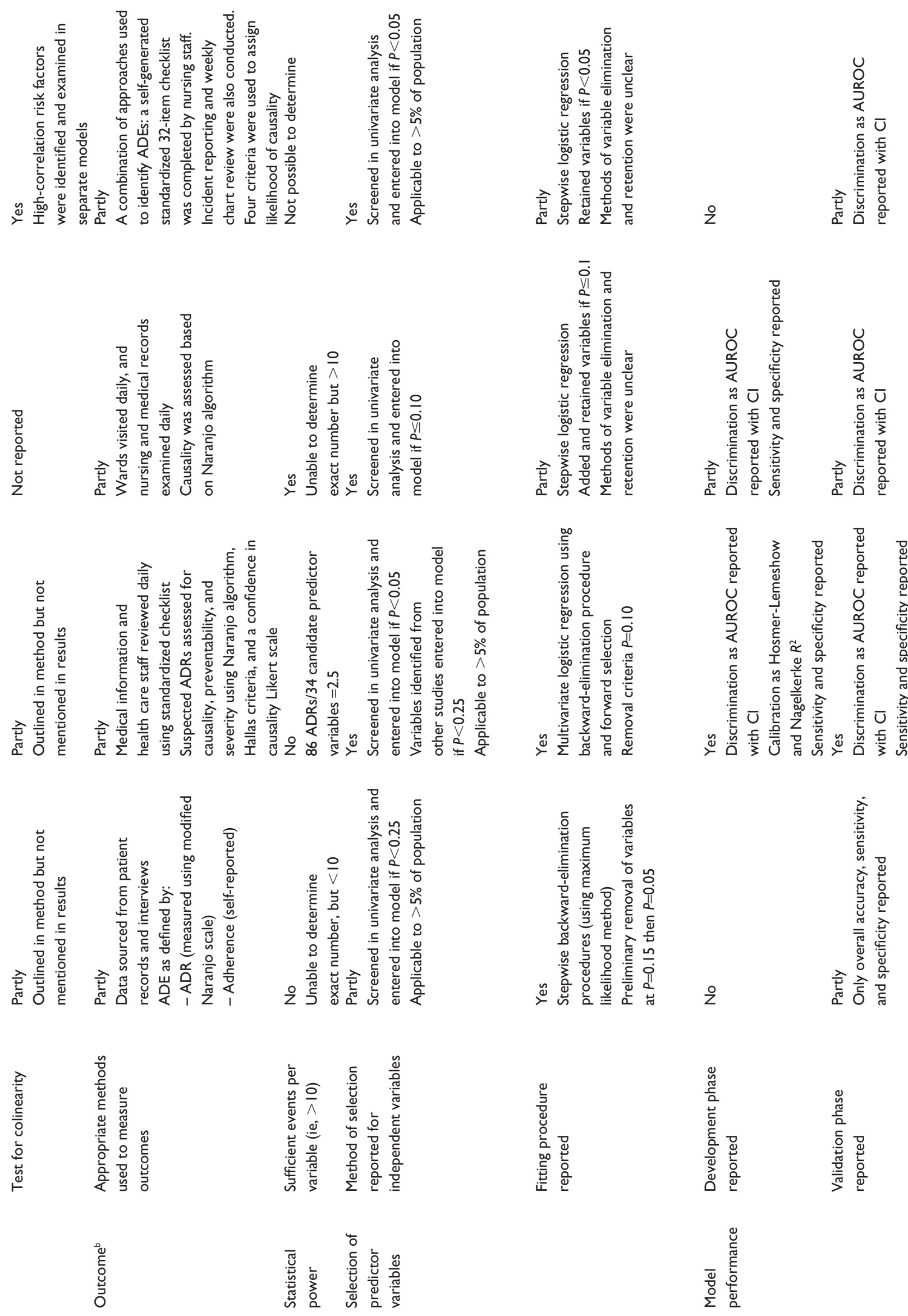

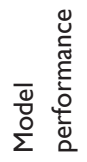




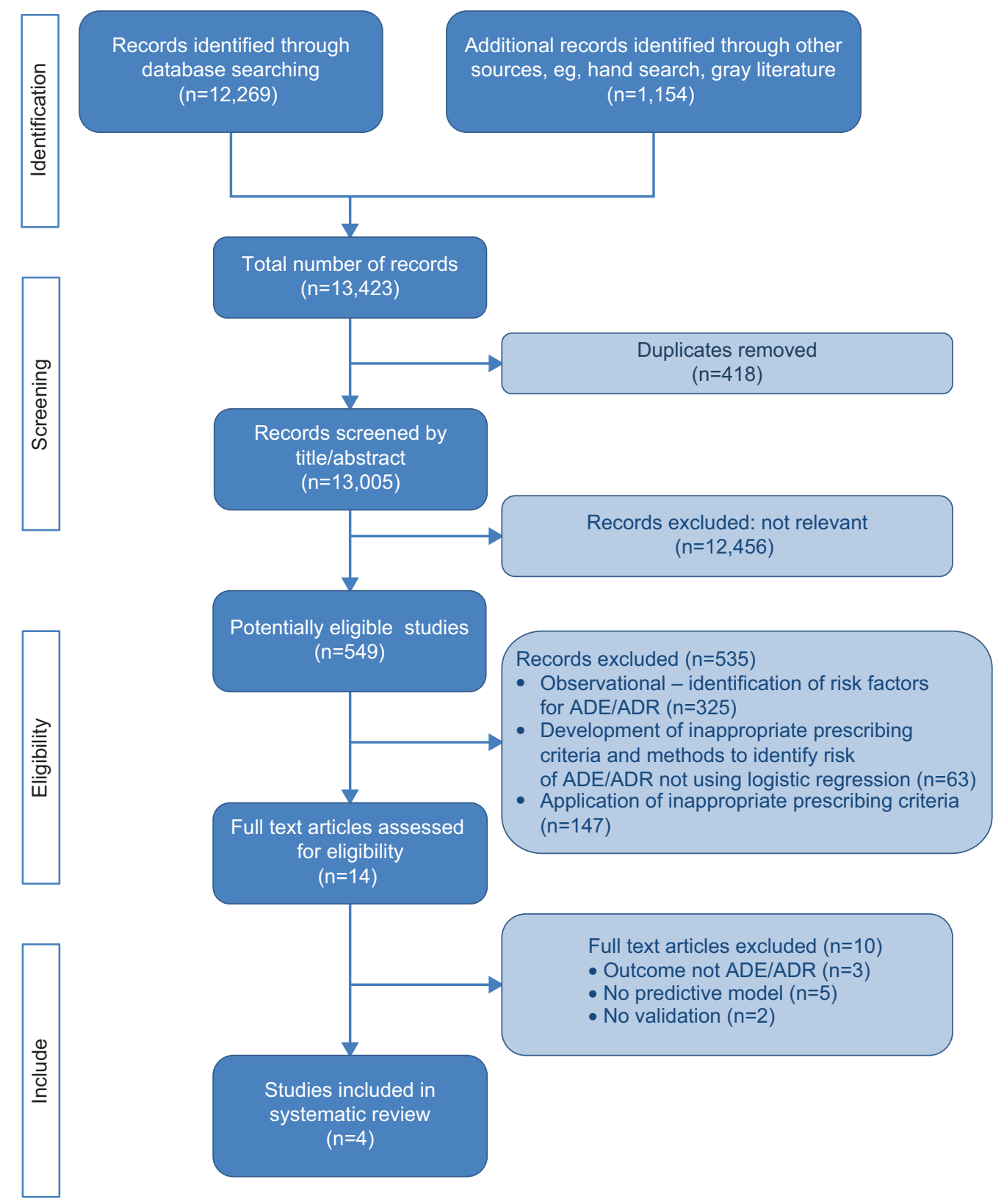

Figure I PRISMA ${ }^{32}$ flow diagram.

Abbreviations: $A D E$, adverse drug event; $A D R$, adverse drug reaction.

\section{Included papers}

\section{Population characteristics}

All included studies were conducted in Western Europe, and only in the hospital setting (acute, community, and rehabilitation hospitals) (Table 1). ${ }^{12-15}$ Two studies represented the very elderly (aged over 80 years). ${ }^{13,15}$ Patient functionality was reported by Onder et al ${ }^{14}$ Tangiisuran, ${ }^{13}$ and McElnay et al ${ }^{12}$ and was measured using patient-perceived health status, Katz Index, and Barthel Index.

The primary outcome in all of the studies was ADR, ${ }^{17}$ with one study using ADE synonymously ${ }^{15}$ and another ${ }^{12}$ including ineffective treatment in an extended definition. The proportion of patients who experienced an ADR/ADE ranged from $6.5 \%$ to $39 \%$, with gastrointestinal, cardiovascular, and nervous systems being those most frequently affected. Medications most frequently associated with ADRs/ADEs included psychotropics, anticoagulants, and analgesics.

\section{Quality assessment - overview}

Whilst all models included the development and validation phases, none addressed the impact and implementation phases. 


\section{Model development}

\section{Study design}

During the development phase, all except Onder et al ${ }^{14}$ used a prospective case-cohort design method, where events accrued over the study period. Onder et al extracted 3 years of data from a historical database, whereas data were extracted over 1-6 months in the other studies. Patient medical notes, in-patient charts, and electronic records were reviewed in the prospective studies. ${ }^{12,13,15}$ In addition, McElnay ${ }^{12}$ asked a sample of the patients about aspects of their medicines, while Trivalle et $a{ }^{15}$ used patient self-reporting as a trigger for further analysis. The validation phase was conducted prospectively for all studies except for that of Trivalle et al where bootstrapping was used.

\section{Participant recruitment}

The criteria for inclusion and exclusion as well as any loss to follow-up were clearly described in all studies, although reporting of patient selection was poor (Table 2). An unknown number of patients were excluded by Onder et al due to incomplete data. ${ }^{14}$

\section{Candidate predictors}

The handling of candidate predictor variables was generally poor. In all studies, the description of the variables was inadequate; where Trivalle et $\mathrm{al}^{15}$ did not report the potential candidate variables, McElnay et $\mathrm{al}^{12}$ Tangiisuran $^{13}$ and Onder et $\mathrm{al}^{14}$ used variables with unclear definitions, eg, "previous ADR". Despite being labeled as a "bad idea", ${ }^{18}$ dichotomization of continuous candidate predictor variables (eg, four or more comorbidities, more than eight medications, previous ADR) was common practice, and may explain the failure to consider conformity to the linear gradient in all ${ }^{12-14}$ but the Trivalle et al study. ${ }^{15}$ Interactions were poorly addressed, as was the coding of variables. Insufficient detail in the results made it difficult to establish whether tests that were mentioned in the methods had been implemented; eg, McElnay et $\mathrm{al}^{12}$ reported testing for interactions and colinearity, but this was not followed through to the results. Predictor-variable measurement was blinded for outcome in the development phase in three of the four studies. ${ }^{12,13,15}$

\section{Outcome}

The occurrence of an ADE/ADR was the primary outcome measure for all studies. A validated assessment of causality, in the form of the Naranjo algorithm ${ }^{19}$ or Hallas criteria, ${ }^{20}$ was adopted by all but Trivalle et al who used their own checklist. ${ }^{15}$ The outcome was recorded in the form of continuous categorical data (ie, unlikely, possible, probable, definite) then collapsed to produce a binary outcome. Possible, probable, and definite were combined as a positive outcome. Blinding to the outcome occurred in all four studies during the validation phase.

\section{Statistical power}

The poor description of potential candidate predictor variables made it impossible to determine if the studies were adequately powered (Table 2 ).

\section{Selection of predictor variables}

The method of selection of predictor variables for inclusion within the multivariable analysis was described in all of the studies (Table 2). Tangiisuran ${ }^{13}$ provided the most detailed description, whilst Trivalle et a ${ }^{15}$ provided the least detailed description. Mixed methods (using the literature, expert opinion, and univariate analysis) were used by Tangiisuran. ${ }^{13}$ Onder et al appeared to have used univariate analysis alone. ${ }^{14}$ There was variation in the significance levels used to retain a predictor variable. ${ }^{12-15}$

\section{Model performance and validation}

The area under the receiver operator curve was used to assess discrimination in three of the four studies, and was $0.70-0.74$ for the development phase. ${ }^{13-15}$ Sensitivity and specificity were reported by Tangiisuran, ${ }^{13}$ Onder et $\mathrm{al}^{14}$ and McElnay et al. ${ }^{12}$ Calibration was only reported by Tangiisuran, ${ }^{13}$ for which Hosmer-Lemeshow was satisfactory but Nagelkerke ${ }^{21}$ was low.

All models underwent the subsequent stage of validation using a second dataset. Internal validation was reported by McElnay et $\mathrm{al}^{12}$ and Trivalle ${ }^{15}$ in the form of split sample and bootstrapping, retrospectively. External validation was performed by Onder et $\mathrm{al}^{14}$ and Tangiisuran ${ }^{13}$ in the same European cohort. Another research group (O'Connor et $\mathrm{al}^{22}$ ) subsequently applied the model developed by Onder et $\mathrm{al}^{14}$ providing additional external validation (Table 1). Area under the receiver operator curve in the validation phase ranged from 0.623 to 0.73 (Table 3). The number of patients involved in the external validation ranged from 204 to $483 .{ }^{12-15,22}$ Only the study by O'Connor et $\mathrm{al}^{22}$ met the recommended minimum number of events (100 events and nonevents).

\section{Score development}

Predictor variables within the final models (Table 3) were attributed a points-based score, which was simplified for practical application. ${ }^{13-15}$ McElnay et al did not proceed to this stage due to the poor performance of their model. ${ }^{12}$ 
Table 3 Summary of final ADR risk-prediction models

\begin{tabular}{|c|c|c|c|c|c|}
\hline Author & $\begin{array}{l}\text { Significant variables in } \\
\text { multivariate analysis }\end{array}$ & Variable coefficient & OR (Cl) & $\begin{array}{l}\text { Attributed } \\
\text { score }\end{array}$ & Validation \\
\hline \multirow[t]{8}{*}{ McElnay et al' ${ }^{12}$} & Prescribed antidepressants & 1.7569 & $5.7942(2.12-15.85)$ & None & Internal (204 patients) \\
\hline & Prescribed digoxin & 0.6884 & $1.9905(1.05-2.33)$ & & Accuracy $63.0 \%$ \\
\hline & Gastrointestinal problems & 0.7704 & $2.1606(1.13-4.15)$ & & Sensitivity $40.5 \%$ \\
\hline & Abnormal potassium level & 0.9455 & $2.5740(1.35-4.91)$ & & Specificity $69.0 \%$ \\
\hline & Thinks drugs were & 1.4375 & $4.2103(2.18-8.14)$ & & \\
\hline & responsible & $-1.786 \mid$ & $0.1676(0.07-0.42)$ & & \\
\hline & Experiences angina & 0.8779 & $2.4057(1.06-5.44)$ & & \\
\hline & Experiences COAD & -1.0997 (constant) & & & \\
\hline \multirow[t]{6}{*}{ Tangiisuran $^{13}$} & Hyperlipidemia & 1.199 & $3.316(1.811-6.072)$ & I & External (483 patients) \\
\hline & Number of medications $\geq 8$ & 1.194 & $3.300(1.927-5.65 I)$ & 1 & Sensitivity $80.0 \%$ \\
\hline & Length of stay $\geq 12$ days & 0.819 & $2.269(1.345-3.826)$ & I & Specificity $55.0 \%$ \\
\hline & Use of hypoglycemic & 0.645 & $1.906(1.040-3.493)$ & I & AUROC $0.73(95 \% \mathrm{Cl} 0.66-0.80)$ \\
\hline & agents & 0.437 & $1.548(0.940-2.548)$ & I & \\
\hline & $\begin{array}{l}\text { High white blood cell } \\
\text { count on admission }\end{array}$ & -3.628 (constant) & & & \\
\hline Onder et $\mathrm{al}^{14}$ & $\geq 4$ comorbidities & Not reported & $1.31(1.04-1.64)$ & I & External (483 patients) \\
\hline \multirow[t]{7}{*}{$\left(\mathrm{O}^{\prime} \text { Connor et al) }\right)^{22}$} & Heart failure & & $1.79(1.39-2.30)$ & I & Sensitivity $68 \%$ \\
\hline & Liver disease & & $1.36(1.06-1.74)$ & I & Specificity $65 \%$ \\
\hline & Number of drugs $\leq 5$ & & I Reference & - & AUROC $0.70(95 \% \mathrm{Cl} 0.63-0.78)$ \\
\hline & Number of drugs $5-7$ & & $1.9(1.35-2.68)$ & 1 & External (5I3 patients) \\
\hline & Number of drugs $\geq 8$ & & $4.07(2.93-5.65)$ & 4 & AUROC $0.623(95 \% \mathrm{Cl} 0.570$ \\
\hline & Previous ADR & & $2.41(1.79-3.23)$ & 2 & $0.676)$ \\
\hline & Renal failure & & $1.21(0.96-1.5 \mathrm{I})$ & 1 & \\
\hline \multirow[t]{7}{*}{ Trivalle et al ${ }^{15}$} & Number of medications & Not reported & $1.9(1.6-2.3)$ & - & Internal (bootstrap) \\
\hline & $0-6$ & & $2.5(1.5-4.1)$ & 0 & AUROC $0.70(95 \%$ Cl 0.65-0.74) \\
\hline & $7-9$ & & $2.0(1.1-1.37)$ & 6 & \\
\hline & $10-12$ & & & 12 & \\
\hline & $\geq 13$ & & & 18 & \\
\hline & Antipsychotic treatment & & & 9 & \\
\hline & Recent anticoagulant & & & 7 & \\
\hline
\end{tabular}

Abbreviations: $A D R$, adverse drug reaction; $A \cup R O C$, area under the receiver operator curve; $\mathrm{Cl}$, confidence interval; $C O A D$, chronic obstructive airways disease; $O R$, odds ratio.

The score developed by Onder et $\mathrm{a}^{14}$ was on a points-based system derived from the odds ratio. There was no assessment to determine if any of the predictive ability was lost in this simplification. Tangiisuran ${ }^{13}$ assigned one point to each predictor variable based on the "variable coefficient being of the same magnitude". It is unclear how Trivalle et al ${ }^{15}$ assigned the values to each predictor variable.

\section{Impact and implementation}

The impact and implementation of these models have not been published, perhaps reflecting their poor to modest performance. McElnay et al recognized the limitation of their level of performance, ${ }^{12}$ and both Tangiisuran and Onder et al called for further external validation of their models. ${ }^{13,14}$ However, Trivalle et $\mathrm{al}^{15}$ concluded that their model could be applied in clinical practice alongside other tools, eg, Mini Mental State Exam. It is also worth considering some of the difficulties highlighted by O'Connor et $\mathrm{al}^{22}$ in the application of Onder et al's ${ }^{14}$ model that are due to unclear definition of predictor variables. ${ }^{14,22}$ Similar challenges are likely to arise when applying results from Tangiisuran, Trivalle et al and McElnay et al given the poorly defined predictor variables. ${ }^{12,13,15}$ The use of variables such as length of stay would also make prospective risk stratification impossible.

\section{Discussion}

Our review suggests that the four models identified, which were designed to predict the risk of older patients suffering an ADR, are not yet suitable for use in clinical practice. While only two (Tangiisuran and Onder et al) were externally validated, their ability to discriminate between those who had experienced an ADR and those who had not was only modest. ${ }^{13,14}$ This could result in a failure to identify patients at high risk of experiencing an ADR. Furthermore, none were subjected to the investigational rigor required when producing a risk-prediction model; in particular, none reported the findings of impact and implementation stages, thus widening the gap between research potential and clinical 
application. Pressures within health care systems are driving a need for robust clinical risk-prediction models to inform care provision, but, to be useful, these models must be of high statistical quality and be clinically relevant.

All four studies had limitations commonly reported in the prognostic research literature. ${ }^{7}$ Three failed to provide sufficient information relating to events-per-variable ratio ${ }^{12,14,15}$ and one was insufficiently powered (Tangiisuran), ${ }^{13}$ so the risk of a type II error (false negative finding) was more likely. ${ }^{23}$ All studies dichotomized their predictor variables (eg, when categorizing the number of medicines) and outcomes (eg, collapsing a continuous ADR causality scale), despite this practice being suboptimal. ${ }^{18,23}$ The use of unrepresentative samples and the management of missing data were also problematic, regardless of whether a retrospective or prospective design was used. In addition, there was often a lack of reporting of candidate predictor variables, which could hinder replication by others. ${ }^{24}$

So, if the current risk prediction models have shortcomings, what can we do to limit older adults experiencing ADEs? Although research investigating medication risk in older adults is widespread, the 535 titles identified in our initial search were often associated with other, mainly system-based, approaches to managing risk, and a substantial proportion were observational in nature. This body of evidence documents the complexity of medication risk in older adults and highlights the multidimensional nature of this field, which includes: clinical aspects, such as the changes in drug handling demonstrated in older age; social risk factors, especially during the transfer of care between different settings; and high-risk medicines, where the risk of medicines are considered but not always balanced against the potential benefits. Furthermore, the difficulty in determining whether a patient has experienced an ADR is challenging given the progressive nature of aging, where functional decline and loss of independence are common. Unfortunately, as older adults are often excluded from clinical trials, this limits our understanding of medicine risk in this population, and can result in inappropriate extrapolation of clinical guidelines, often based on research in younger patients.

So, is there a place for risk models in this care setting? A more common strategy is to adopt a systems approach to medicines use where pharmacological appropriateness is monitored, usually by applying a list of prescribing indicators: for example, Beer's criteria. ${ }^{16}$ The recognized limitations of such an approach are that it is time-consuming if used in routine care and can be viewed as one-dimensional. This focus on specific medicines often restricts, due to formulary and licensing issues, value in an international context. Perhaps the way forward is a hybrid whereby risk models bring a multidimensional perspective to guide clinical intervention, delivered as part of an integrated system built around the principles of medication safety. If models can map this complex interplay between clinical, social, and medication-related variables to stratify an individual's risk of a future ADE, they may become a useful decision support tool for clinicians and patients to be used alongside systems-based approaches. This approach could help prioritize interventions for those patients at highest risk. Ultimately, the variables associated with medication risk, eg, polypharmacy and renal impairment, are inherent in clinical decisions and form part of a clinician's intuitive risk assessment when prescribing medicines. Furthermore, clinicians often modify decisions based on individual variability, whereas a statistical model may not be able to accommodate the clinical nuances and overcome the gerontological phenomenon of age heterogeneity. ${ }^{25}$ While risk prediction models are not intended to replace clinicians' decisions, they should not stratify patients less accurately than clinicians. It would be helpful if future work could compare a clinician's risk stratification against that of an ADR riskprediction model. This work would help inform the clinical relevance of the model and contribute to the impact and implementation research that is thus far lacking. In the meantime, useful strategies that clinicians may adopt to prevent ADRs occurring are: ensuring that reliable medicines reconciliation is undertaken; avoiding the prescribing cascade (where a drug is prescribed to manage the problem caused by another); and the routine optimization of drug use in line with renal and liver function.

While conducting this systematic review, we could not assess for publication bias using conventional methods such as funnel plots due to the small number of studies available. ${ }^{26}$ Publication bias in favor of positive results has been raised as a significant problem in the area of cancer risk-prediction research, and it is likely to be present in this area in which negative results remain unpublished. ${ }^{27}$ The proposal to develop reporting guidelines that stipulate registration of all risk-prediction research should go some way in reducing future reporting bias. ${ }^{28}$ These guidelines could also be applied to protocols and manuscripts when designing or publishing risk-prediction research, and may be a more suitable tool for quality assessment in the future. ${ }^{29}$ In the absence of a consensus guideline, we used an amalgamation of standards for reporting risk-prediction research to carry out this review. This approach should reduce the likelihood of any important quality measures being excluded. In the future, recommendations developed by the Cochrane Prognosis Methods Group 
and the Prognosis Research Strategy Partnership should assist investigators in combating the challenges present when conducting risk-prediction research. 23,28,29

\section{Conclusion}

Risk stratification is attractive, especially in older patients where the population is growing and placing an increased demand on the health care service, a service that is woefully underprepared for the projected global growth to over 2 billion people over the age of 60 years by $2050 .{ }^{30} \mathrm{We}$ identified four ADR risk-prediction models with poor to modest performance and raised questions about their overall quality, a finding not uncommon in the area of risk-prediction research. If these models are to be embraced as part of routine clinical care, further work needs to be conducted so that external validity can be assured and a practical approach upheld. Only then can implementation and impact be assessed with the view to adoption as part of a systems approach within routine clinical care.

\section{Disclosure}

The authors report no conflicts of interest in this work.

\section{References}

1. Pirmohammed M, James S, Meakin S, et al. Adverse drug reactions as a cause of admission to hospital: prospective analysis of 18,820 patients. BMJ. 2004;329:15-19.

2. Budnitz DS, Pollock DA, Weidenbach KN, et al. National surveillance of emergency department visits for outpatient adverse drug events. JAMA. 2006;296:1858-1866.

3. Mangoni AA, Jackson SH. Age-related changes in pharmacokinetics and pharmacodynamics: basic principles and practical applications. $\mathrm{Br}$ J Clin Pharmacol. 2004;57:6-14.

4. Davies EC, Green CF, Taylor S, Williamson PR, Mottram DR, Pirmohamed M. Adverse drug reactions in hospital in-patients: a prospective analysis of 3695 patient episodes. PLoS One. 2009;4:e4439.

5. Camm AJ, Lip GY, De Caterina R, et al. 2012 focused update of the ESC Guidelines for the management of atrial fibrillation. Developed with the special contribution of the European Heart Rhythm Association. Eur Heart J. 2012;33:2719-2747.

6. The John Hopkins ACG $^{\circledR}$ System: International Experience [webpage on the Internet]. Baltimore: Johns Hopkins University; 2013. Available from: http://acg.jhsph.org/index.php?option=com_content\&view=artic le\&id=73\&Itemid=138. Accessed April 15, 2013.

7. Toll DB, Janssen KJM, Vergouwe Y, Moons KG. Validation, updating and impact of clinical prediction rules: a review. J Clin Epidemiol. 2008;61:1085-1094.

8. Yourman LC, Lee SJ, Schonberg MA, Widera EW, Smith AK. Prognostic indicies for older adults. A systematic review. JAMA. 2012;307:182-192.

9. Bagley SC, White H, Golomb BA. Logistic regression in the medical literature: standards for use and reporting, with particular attention to one medical domain. J Clin Epidemiol. 2001;54:979-985.

10. Critical Appraisal Skills Programme for Clinical Prediction Rules [homepage on the Internet]. Available from: http://www.casp-uk.net. Accessed November 9, 2011.
11. Steyerberg EW. Clinical Prediction Models: a practical approach to development, validation and updating. New York: Springer; 2010.

12. McElnay JC, McCallion CR, Al-Deagi F, Scott MG. Development of a risk model for adverse drug events in the elderly. Clin Drug Invest. 1997; 13:47-55.

13. Tangiisuran B. Predicting adverse drug reactions in the hospitalised elderly [PhD Thesis]. Brighton: University of Sussex; 2009.

14. Onder G, Petrovic M, Tangiisuran B, et al. Development and validation of a score to assess risk of adverse drug reactions among in-hospital patients 65 years or older: The GerontoNet ADR Risk Score. Arch Intern Med. 2010;170:1142-1148.

15. Trivalle C, Burlaud A, Ducimetière P; The IMEPAG Group 1. Risk factors for adverse drug events in hospitalised elderly patients: a geriatric score. Eur Geriatr Med. 2011;2:284-289.

16. American Geriatrics Society 2012 Beers Criteria Update Expert Panel. American Geriatrics Society updated Beers Criteria for potentially inappropriate medication use in older adults. J Am Geriatr Soc. 2012;60:616-631.

17. World Health Organization. International Drug Monitoring: The Role of National Centres (World Health Organization Technical Report Series No. 498). Geneva: World Health Organization; 1972.

18. Royston P, Altman DG, Sauerbrei W. Dichotomizing continuous predictors in multiple regression: a bad idea. Stat Med. 2006;25: 127-141.

19. Naranjo CA, Busto U, Sellers EM, et al. A method for estimating the probability of adverse drug reactions. Clin Pharmacol Ther. 1981;30(2):239-245.

20. Hallas J, Harvald B, Gram LF, et al. Drug related hospital admissions: the role of definitions and intensity of data collection and the possibility of prevention. J Intern Med. 1990;228:83-90.

21. Field A. Discovering Statistics Using IBM SPSS Statistics. 4th edition. London: Sage; 2013.

22. O'Connor MN, Gallgher P, Byrne S, O'Mahony D. Adverse drug reactions in older patients during hospitalisation: are they predictable? Age Ageing. 2012;41:771-776.

23. Hingorani AD, Windt DA, Riley RD, et al. Prognosis research strategy (PROGRESS) 4: stratified medicine research. BMJ. 2013;346:e5793.

24. Siontis GC, Tzoulaki I, Siontis KC, Ioannidis JP. Comparisons of established risk prediction models for cardiovascular disease: systematic review. BMJ. 2012;344:e3318.

25. Nelson EA, Dannefer D. Age heterogeneity: fact or fiction? The fate of diversity in gerontological research. Gerontologist. 1992;32:17-23.

26. Macaskill P, Walter SD, Irwig L. A comparison of methods to detect publication bias in meta-analysis. Stat Med. 2001;20:641-654.

27. Hemingway H, Riley RD, Altman DG. Ten steps towards improving prognosis research. BMJ. 2009;339:b4184.

28. Steyerberg EW, Moons KG, van der Windt DA, et al. Prognosis research strategy (PROGRESS) 3: prognostic model research. PLoS Med. 2013;10:e1001381.

29. Geersing G-J, Bouwmeester W, Zuithoff P, Spijker R, Leeflang M, Moons KG. Search filters for finding prognostic and diagnostic prediction studies in medline to enhance systematic reviews. PLoS One. 2012;7:e32844.

30. World Health Organization. World Health Day 2012 Toolkit for Organizers (webpage on the Internet). Geneva: World Health Organization; 2012. Available from: http://www.who.int/world-health-day/2012/ toolkit/background/en/index.html. Accessed August 30, 2012.

31. Onder G, Pedone C, Landi F, et al. Adverse drug reactions as cause of hospital admissions: results from the Italian Group of Pharmacoepidemiology in the Elderly (GIFA). J Am Geriatr Soc. 2002;50(12): 1962-1968.

32. Moher D, Liberati A, Tetzlaff J, Altman DG; The PRISMA Group. Preferred reporting items for systematic reviews and meta-analyses: the PRISMA statement. BMJ. 2009;151(4):264-269. 


\section{Supplementary materials}

Table SI Embase search strategy indicating the order in which the terms were entered and how they were combined

Risk tool

I. risk assessment.mp. [ $\mathrm{mp}$ = title, abstract, subject headings, heading word, drug trade name, original title, device manufacturer, drug manufacturer, device trade name, keyword]

2. exp prediction/

3. exp scoring system/

4. exp clinical assessment tool/

5. exp risk factor/

6. exp risk management/

7. $\exp$ decision support system/

8. risk stratification.mp. [ $\mathrm{mp}=$ title, abstract, subject headings, heading word, drug trade name, original title, device manufacturer, drug manufacturer, device trade name, keyword]

9. I or 2 or 3 or 4 or 5 or 6 or 7 or $8^{a}$

Medication related problem

10. exp adverse drug reaction/

II. adverse drug event*.mp. [mp = title, abstract, subject headings, heading word, drug trade name, original title, device manufacturer, drug manufacturer, device trade name, keyword]

12. adverse drug reaction*.mp. [mp = title, abstract, subject headings, heading word, drug trade name, original title, device manufacturer, drug manufacturer, device trade name, keyword]

13. medication related problem*.mp. [mp = title, abstract, subject headings, heading word, drug trade name, original title, device manufacturer, drug manufacturer, device trade name, keyword]

14. drug related problem*.mp. [mp = title, abstract, subject headings, heading word, drug trade name, original title, device manufacturer, drug manufacturer, device trade name, keyword]

15. exp medication therapy management/

16. drug/ae [Adverse Drug Reaction]

17. exp polypharmacyl

18. exp medication error/ae, pc [Adverse Drug Reaction, Prevention]

19. inappropriate prescri*.mp. [mp = title, abstract, subject headings, heading word, drug trade name, original title, device manufacturer, drug manufacturer, device trade name, keyword]

20. (readmission and drugs).mp. [mp = title, abstract, subject headings, heading word, drug trade name, original title, device manufacturer, drug manufacturer, device trade name, keyword]

2I. patient compliance.mp. [mp = title, abstract, subject headings, heading word, drug trade name, original title, device manufacturer, drug manufacturer, device trade name, keyword]

22. 10 or 11 or 12 or 13 or 14 or 15 or 16 or 17 or 18 or 19 or 20 or $21^{2}$

Elderly

23. aged/

24. exp aging/

25. exp elderly care/

26. older people.mp.

27. older person.mp.

28. aged over $80 . \mathrm{mp}$.

29. 23 or 24 or 25 or 26 or 27 or 28 or $29^{a}$

Combined terms

30. 9 and 22 and $29^{a}$

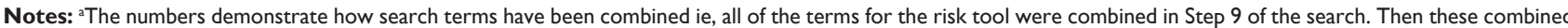
terms were combined with those from all those relating to medication related problems ie, Step 22 and with terms relating to elderly ie, Step 29 . This resulted in a combined search of the terms listed in Steps 9 and 22 and 29.

Abbreviations: exp, explode all trees; mp, multiple posting. 
Table S2 Criteria to consider when evaluating the quality of risk prediction models

\begin{tabular}{|c|c|c|}
\hline $\begin{array}{l}\text { Standard } \\
\text { criteria }^{\mathrm{a}}\end{array}$ & Explanation & Example \\
\hline Study design & $\begin{array}{l}\text { Prospective: allows optimal collection of potential candidate variables; } \\
\text { smaller dataset often generated. } \\
\text { Retrospective: enables use of large previously collected datasets; quality } \\
\text { of candidate variable data may be compromised due to missing data, } \\
\text { which rarely occurs at random. }\end{array}$ & $\begin{array}{l}\text { Prospective study design, } n=690 \text {, } \\
\text { all exclusions were for appropriate } \\
\text { reasons.' } \\
\text { Retrospective study design, } n=5,936 \text {, } \\
\text { unknown number of exclusions due to } \\
\text { missing data. }^{2}\end{array}$ \\
\hline $\begin{array}{l}\text { Participant } \\
\text { recruitment }\end{array}$ & $\begin{array}{l}\text { Inclusion and exclusion criteria should be clearly described to allow full } \\
\text { assessment of patient population studied. } \\
\text { Any systematic variation in recruitment of patients should be viewed } \\
\text { with caution due to risk of sampling bias. } \\
\text { There is no predetermined satisfactory number for loss to follow-up; }\end{array}$ & $\begin{array}{l}\text { Interview data was only collected for half } \\
\text { of the patients during the development } \\
\text { phase. } \\
\text { Patients not wishing to participate in the } \\
\text { interview may systematically differ. }\end{array}$ \\
\hline
\end{tabular}

Candidate predictor variables

Outcome

Statistical power

Selection of variables

Model performance however, it should be considered that missing data impacts on the statistical power of the study.

Variables and their measurement should be clearly defined to allow for replication.

Investigators should be blind to outcome to reduce risk of bias.

Continuous variables should be assessed for conformity to linear gradient.

Not necessary for dichotomous variables; however, dichotomization of continuous variables not recommended as it impacts on the statistical power of the study.

Correlation (test for colinearity) between risk variables should be examined and reported.

Method of measuring outcome: must be reproducible and, where assessment scales are applied, these should be validated to increase accuracy and reproducibility of the measurement. Dichotomization of continuous outcomes is not recommended as it can affect statistical power.

Sample size is calculated based on number of outcome events per variable, where ten events per variable is often recommended. A high number of variables and a rare outcome can result in over-fitting of the model, causing poor generalizability.

Independent variable selection should be described clearly, and can be based on the literature and/or statistical association as determined by univariate analysis with outcome variable. Selection based upon univariate analysis alone increases likelihood of developing an over-fitted model. Inclusion of variables applicable to over $5 \%$ of population may help exclude artifact variables.

Fitting procedure (entering of variables into model) should be explicitly stated, including removal criteria.

In both development and validation phases, assessment of discrimination and calibration should be reported to determine how well the model distinguishes those who have an ADR from those who have not, as well as how close the prediction is to the observed outcome for that risk group.

AUROC $>0.7$ is often deemed acceptable, but this alone is not sufficient to determine the clinical usefulness of the model. ${ }^{6}$

Assessment of the generalizability of the model is important to determine the accuracy of predictions in another population and is recommended prior to routine clinical application. Internal validation, by methods such as bootstrapping (data resampling) or split-sample, assesses how well predictors correspond to the outcome, but leads to optimistic estimates of model performance. External validation is more rigorous and enables assessment of accuracy when the model is applied by investigators not involved in the development of the model.
Unclear how key variables, eg, liver disease, were defined. To replicate, study investigators would be required to apply their own definition, which may have an impact on reproducibility. ${ }^{2}$

Investigators generated own causality assessment of unknown validity. ${ }^{4}$ Applied widely-used validated causality assessment (Naranjo algorithm). ${ }^{2}$

Reported 86 ADRs in a sample of 690 patients and assessed 34 candidate predictor variables, resulting in only 2.5 events per variable.'

Variables were entered into multivariate analysis if $P<0.05$ after univariate analysis, or if $P<0.25$ for variables identified from other studies. Liver disease was removed as it applied to $<5 \%$ of population. Backward elimination and forward selection were used with a removal criteria of $P=0.10$.'

Discrimination (AUROC) and calibration (Hosmer-Lemeshow) reported in the development and validation phases.' Trivalle applied bootstrapping. ${ }^{5}$ Onder applied external validation whereby the model was applied by investigators not involved in the development of the model and in a different geographical location.

Note: ${ }^{a}$ Criteria derived from the published literature. ${ }^{8-11}$

Abbreviations: ADR, adverse drug reaction; AUROC, area under the receiver operator curve. 


\section{References}

1. Siontis GC, Tzoulaki I, Siontis KC, Ioannidis JP. Comparisons of established risk prediction models for cardiovascular disease: systematic review. BMJ. 2012;344:e3318.

2. Nelson EA, Dannefer D. Age heterogeneity: fact or fiction? The fate of diversity in gerontological research. Gerontologist. 1992;32:17-23.

3. Hingorani AD, Windt DA, Riley RD, et al. Prognosis research strategy (PROGRESS) 4: stratified medicine research. BMJ. 2013;346:e5793.

4. Macaskill P, Walter SD, Irwig L. A comparison of methods to detect publication bias in meta-analysis. Stat Med. 2001;20:641-654.

5. Trivalle C, Burlaud A, Ducimetière P; The IMEPAG Group 1. Risk factors for adverse drug events in hospitalised elderly patients: a geriatric score. Eur Geriatr Med. 2011;2:284-289.

6. Field A. Discovering Statistics Using IBM SPSS Statistics. 4th edition. London: Sage; 2013.
7. Onder G, Petrovic M, Tangiisuran B, et al. Development and validation of a score to assess risk of adverse drug reactions among in-hospital patients 65 years or older: The GerontoNet ADR Risk Score. Arch Intern Med. 2010;170:1142-1148.

8. Yourman LC, Lee SJ, Schonberg MA, Widera EW, Smith AK. Prognostic indicies for older adults. A systematic review. JAMA. 2012; 307:182-192.

9. Bagley SC, White H, Golomb BA. Logistic regression in the medical literature: standards for use and reporting, with particular attention to one medical domain. J Clin Epidemiol. 2001;54:979-985.

10. Critical Appraisal Skills Programme for Clinical Prediction Rules [homepage on the Internet]. Available from: http://www.casp-uk.net. Accessed November 9, 2011.

11. Steyerberg EW. Clinical Prediction Models: a practical approach to development, validation and updating. New York: Springer; 2010.
Clinical Interventions in Aging

\section{Publish your work in this journal}

Clinical Interventions in Aging is an international, peer-reviewed journal focusing on evidence-based reports on the value or lack thereof of treatments intended to prevent or delay the onset of maladaptive correlates of aging in human beings. This journal is indexed on PubMed Central, MedLine,

\section{Dovepress}

CAS, Scopus and the Elsevier Bibliographic databases. The manuscript management system is completely online and includes a very quick and fair peer-review system, which is all easy to use. Visit http://www.dovepress. $\mathrm{com} /$ testimonials.php to read real quotes from published authors. 